\title{
Metabolic and ventilatory response pattern to arm elevation in patients with COPD and healthy age-matched subjects
}

\author{
E.M. Baarends*, A.M.W.J. Schols*, D-J. Slebos*, R. Mostert**, \\ P.P. Janssen**, E.F.M. Wouters*
}

Metabolic and ventilatory response pattern to arm elevation in patients with COPD and healthy age-matched subjects. E.M. Baarends, A.M.W.J. Schols, D-J. Slebos, R. Mostert, P.P. Janssen, E.F.M. Wouters. (C)ERS Journals Ltd 1995.

ABSTRACT: Many patients with chronic obstructive pulmonary disease (COPD) experience problems in those activities of daily living which involve so-called unsupported arm elevations (AE). In this study, possible differences in the metabolic and ventilatory response pattern to three types of arm elevation were compared between 13 COPD patients (forced expiratory volume in one second (FEV1) (mean (SD)) 38 (13) \% of predicted) and 13 age-matched healthy subjects.

Each subject consecutively performed three types of arm elevation for $2 \mathrm{~min}$, with 3 min rest periods in between. Breath-by-breath metabolic and ventilatory parameters and heart rate (HR) were registered during a 3 min baseline period and throughout the measurement period.

Adjusted for significantly greater baseline test results in COPD patients, it was found that $\mathrm{AE}$ (arm elevation including recovery) tended to be more demanding with respect to metabolic and ventilatory response for patients with COPD than for the age-matched healthy subjects. Arm elevation resulted in an increase in oxygen consumption $\left(V^{\prime} \mathrm{O}_{2}\right)(\mathrm{COPD} 12 \%$; healthy $6 \%)$, carbon dioxide elimination $V^{\prime} \mathrm{CO}_{2}$ (COPD 15\%; healthy 10\%), minute ventilation $V^{\prime} \mathrm{E}$ (COPD 13\%; healthy $7 \%$ ) and heart rate (COPD 2\%; healthy $5 \%$ ). A pronounced difference was found in the pattern of metabolic and ventilatory response to arm elevation, i.e. there was an earlier but sluggish $V^{\prime} \mathrm{O}_{2}$ onset in COPD patients, whereas the healthy subjects demonstrated a sudden peak approximately $30 \mathrm{~s}$ after arm elevations. Mutual comparison of the three different types of arm elevation demonstrated a comparable response pattern.

Knowledge of the specific response to arm elevations in COPD patients seems essential for interpretation of arm elevation tests in upper extremity rehabilitation programmes.

Eur Respir J., 1995, 8, 1345-1351.
*Dept of Pulmonology, University of Limburg, Maastricht, The Netherlands. **Asthma centre Hornerheide, Horn, The Netherlands.

Correspondence: E.M. Baarends Dept of Pulmonology

University Hospital Maastricht

P.O. Box 5800

6202 AZ Maastricht

The Netherlands

Keywords: Arm elevation

chronic obstructive pulmonary disease metabolism

muscle

ventilation

Received: August 221994

Accepted after revision March 261995
Patients with severe chronic obstructive pulmonary disease (COPD) often complain of dyspnoea during activities of daily living, such as combing their hair, brushing their teeth or shaving [1-3]. These activities mainly involve (unsupported) movements of arm and shoulder muscles.

Several factors may contribute to impairment of unsupported arm activities in COPD patients, such as a dual activity of shoulder muscles in breathing as well as movement $[4,5]$, and peripheral [6] and respiratory [7] skeletal muscle weakness.

In order to examine the possible limitations of (unsupported) arm activities in patients with COPD, other investigators have studied the metabolic and ventilatory requirements of simple arm elevation. In all studies, arm elevation resulted in a significant increase in metabolic and ventilatory requirements $[3,4,5,8]$. Possible differences in metabolic and ventilatory response pattern following arm elevation between COPD patients and healthy persons, however, have not yet been specified. Furthermore, it may be hypothesized that the response pattern depends on the type of arm elevation due to different muscle recruitment.

In this study, the metabolic and ventilatory requirements of three basic arm elevations were compared between COPD patients and healthy age-matched control subjects.

\section{Material and methods}

\section{Study population}

Thirteen male patients with severe COPD participating in an in-patient pulmonary rehabilitation programme were studied (characteristics are given in table 1). The diagnosis of COPD was made by history, physical 
Table 1. - Physiological and metabolic characteristics of the groups studied

\begin{tabular}{lccc}
\hline Variables & $\begin{array}{c}\text { COPD } \\
(\mathrm{n}=13)\end{array}$ & $\begin{array}{c}\text { Control } \\
(\mathrm{n}=13)\end{array}$ & $\mathrm{p}$-value \\
\hline Age yrs & $64 \pm 6$ & $65 \pm 7$ & $\mathrm{NS}$ \\
FEV1 \% pred & $38 \pm 13$ & $101 \pm 13$ & $* * *$ \\
FVC \% pred & $90 \pm 15$ & $113 \pm 10$ & $* * *$ \\
$P \mathrm{I}, \mathrm{max} \mathrm{kPa}$ & $7.4 \pm 1.4$ & $9.7 \pm 2.1$ & $* *$ \\
Weight kg & $66.8 \pm 9.9$ & $81.5 \pm 9.8$ & $* *$ \\
BMI kg.m ${ }^{-2}$ & $21.7 \pm 2.9$ & $27.6 \pm 5.8$ & $* *$ \\
FFMI kg.m ${ }^{-2}$ & $16.5 \pm 1.7$ & $20.2 \pm 3.3$ & $* * *$ \\
REE-ACT kcal $\cdot 24 \mathrm{~h}^{-1}$ & $1614 \pm 238$ & $1643 \pm 140$ & $\mathrm{NS}$ \\
ADJ-REE kcal $\cdot 24 \mathrm{~h}^{-1}$ & $1744 \pm 243$ & $1529 \pm 116$ & $* *$ \\
\end{tabular}

Data are presented as mean \pm SD. BMI: body mass index; FFMI: fat free mass index (fat-free mass divided by height ${ }^{2}$ ); REEACT: actual resting energy expenditure; ADJ-REE: REE adjusted for FFM [10]; FEV1: forced expiratory volume in one second; FVC: forced vital capacity; $P_{\mathrm{I}, \mathrm{max}}$ : maximal inspiratory mouth pressure; $\%$ pred: percentage of predicted value; COPD: chronic obstructive pulmonary disease. $*$ : $\mathrm{p}<0.05$; **: $\mathrm{p}<0.01 ; * * *: \mathrm{p}<0.001 ;$ Ns: not significant.

examination, and pulmonary function tests according to the criteria of the American Thoracic Society [9]. All patients had severe airflow obstruction (forced expiratory volume in one second $(\mathrm{FEV} 1)<50 \%$ of predicted values) [9]. The patients were in a stable clinical condition.

Thirteen age-matched, healthy, male control subjects were recruited (table 1), and were tested under the same conditions.

\section{Physiologic and metabolic profile}

FEV1 and forced vital capacity (FVC) were measured (Masterlab®, Jaeger, Wurzburg, Germany). The highest value of at least three spirometric manoeuvres was used and expressed as percentage of the reference value [11]. Inspiratory muscle strength was measured in patients and controls by determining maximal inspiratory mouth pressures $\left(P_{\mathrm{I}, \max }\right)$ according to the technique described by Black and Hyatt [12].

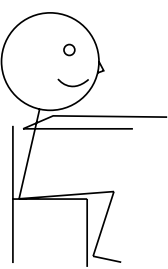

$\mathrm{AE} 1$

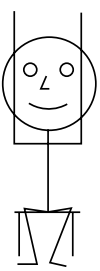

$\mathrm{AE} 2$

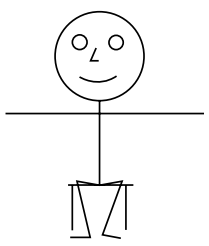

$\mathrm{AE} 3$
Fig. 1. - Types of arm elevation (AE) studied. AE1: 90 degrees elevation of extended arms in the frontal plane; $\mathrm{AE} 2$ : 180 degrees elevation of extended arms in the frontal plane; AE3: 90 degrees abduction with extended arms.

Resting energy expenditure (REE) was measured by indirect calorimetry using a ventilated hood system (Oxyconbeta ${ }^{\circledR}$, Mijnhardt, Bunnik, The Netherlands). Measurements were performed in the early morning (between 8.00 and 9.30 a.m.) in the fasting state [10].

Fat-free mass (FFM) was assessed by bioelectrical resistance measurements (BIA 101®, RJL Systems, Detroit, USA) at the right side while patients were in the supine position, as described by LUKASKI et al. [13]. FFM was calculated using a patient specific regression equation, as described by ScHOLs et al. [14].

\section{Arm elevation (AE) testing}

Three basic arm elevations, i.e. a static position held for 2 min, were compared (fig. 1): 90 degrees elevation of extended arms in the frontal plane (AE1); 180 degrees elevation of extended arms in the frontal plane (AE2); and 90 degrees abduction with extended arms (AE3). The test procedure was as follows: firstly, the subject sat quietly on a chair for a 3 min baseline measurement with arms down on the knees. This was followed by 2 min of AE1, $\mathrm{AE} 2$, and then $\mathrm{AE} 3$ with 3 min rest periods in between, and 2 min rest after AE3. During AEs and resting periods, heart rate was continuously measured with a sporttester (PE 3000®, Polar Electro cy, Kempele, Finland). Oxygen consumption, carbon dioxide production, tidal volume, and breathing frequency were measured breath-bybreath with an automated system (Oxyconbeta®, Mijnhardt, Bunnik, The Netherlands).

Table 2. - Percentage increase in metabolic and ventilatory requirements following the three types of arm elevation $(\mathrm{AE})$

\begin{tabular}{lcccccc}
\hline & \multicolumn{2}{c}{ AE1 } & \multicolumn{2}{c}{ AE2 } & \multicolumn{2}{c}{ AE3 } \\
& COPD & Control & COPD & Control & COPD & Control \\
\hline$V^{\prime} \mathrm{O}_{2}$ & $12 \pm 5^{*}$ & $6 \pm 3^{*}$ & $14 \pm 6$ & $5 \pm 5$ & $14 \pm 6$ & $5 \pm 5$ \\
$V^{\prime} \mathrm{CO}_{2}$ & $15 \pm 18^{* *}$ & $10 \pm 3^{*}$ & $21 \pm 22$ & $11 \pm 5$ & $21 \pm 23$ & $11 \pm 6$ \\
$\mathrm{RQ}$ & $3 \pm 1^{* *}$ & $4 \pm 1^{*}$ & $6 \pm 1$ & $7 \pm 1$ & $7 \pm 1$ & $6 \pm 2$ \\
$V^{\prime} \mathrm{E}$ & $13 \pm 6^{*}$ & $7 \pm 2^{*}$ & $18 \pm 6$ & $7 \pm 4$ & $20 \pm 7$ & $7 \pm 4$ \\
$V_{\mathrm{T}}$ & $4 \pm 4$ & $3 \pm 4$ & $9 \pm 6$ & $2 \pm 4$ & $7 \pm 5$ & $6 \pm 6$ \\
$f_{\mathrm{R}}$ & $8 \pm 6$ & $5 \pm 3$ & $10 \pm 7$ & $5 \pm 3$ & $13 \pm 6$ & $2 \pm 4$ \\
$\mathrm{HR}$ & $2 \pm 2^{*}$ & $5 \pm 7^{*}$ & $2 \pm 2$ & $7 \pm 9$ & $1 \pm 4$ & $6 \pm 6$ \\
\hline
\end{tabular}

Data are presented as mean $\pm \mathrm{SD} . \quad V^{\prime} \mathrm{O}_{2}$ : oxygen consumption; $V^{\prime} \mathrm{CO}_{2}$ : carbon dioxide production; RQ: respiratory exchange ratio; $V^{\prime}$ E: minute ventilation; $V \mathrm{~T}$ : tidal volume; $f_{\mathrm{R}}$ : breathing frequency; HR: heart rate; COPD: chronic obstructive pulmonary disease; AE1: 90 degrees elevation of extended arms in the frontal plane; AE2: 180 degrees elevation of extended arms in the frontal plane; AE3: 90 degrees abduction with extended arms. *: $\mathrm{p}<0.05$; **: $\mathrm{p}<0.01 ; * * *: \mathrm{p}<0.001$ significantly different from baseline measurement. 
Healthy
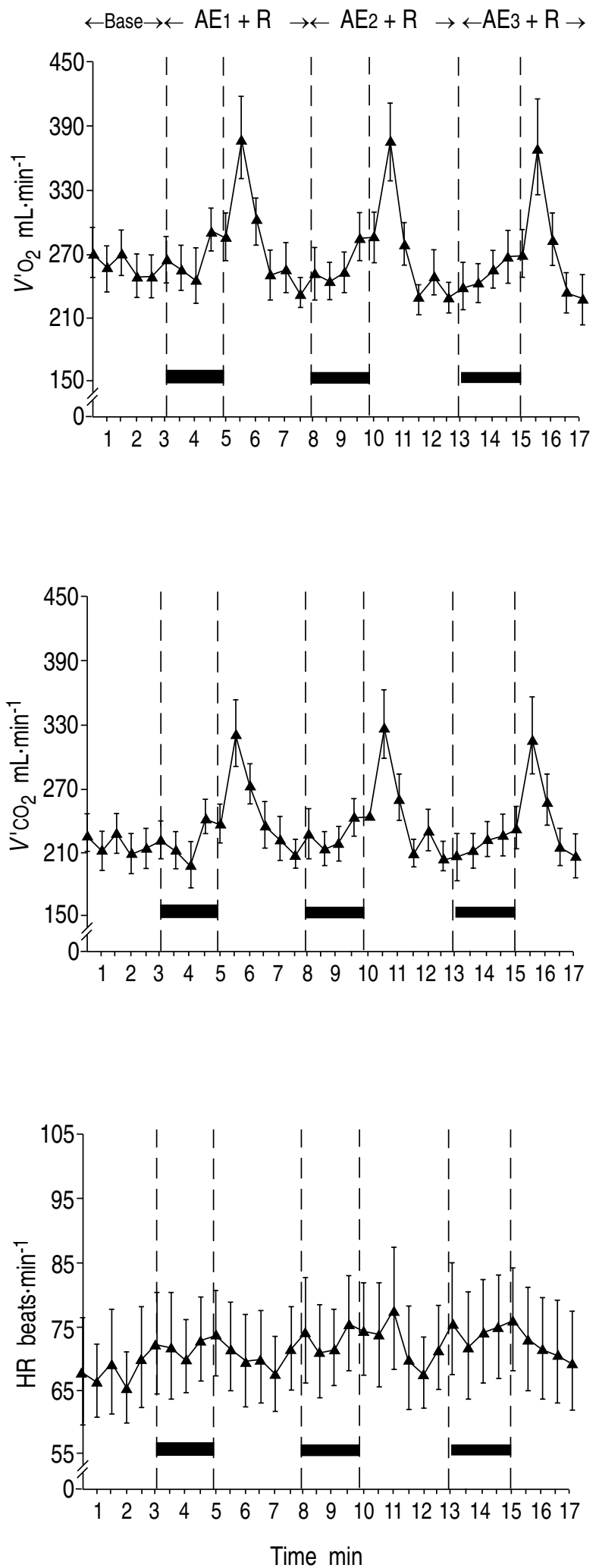

COPD

$\leftarrow$ Base $\rightarrow \leftarrow \mathrm{AE} 1+\mathrm{R} \rightarrow \leftarrow \mathrm{AE} 2+\mathrm{R} \rightarrow \leftarrow \mathrm{AE} 3+\mathrm{R} \rightarrow$
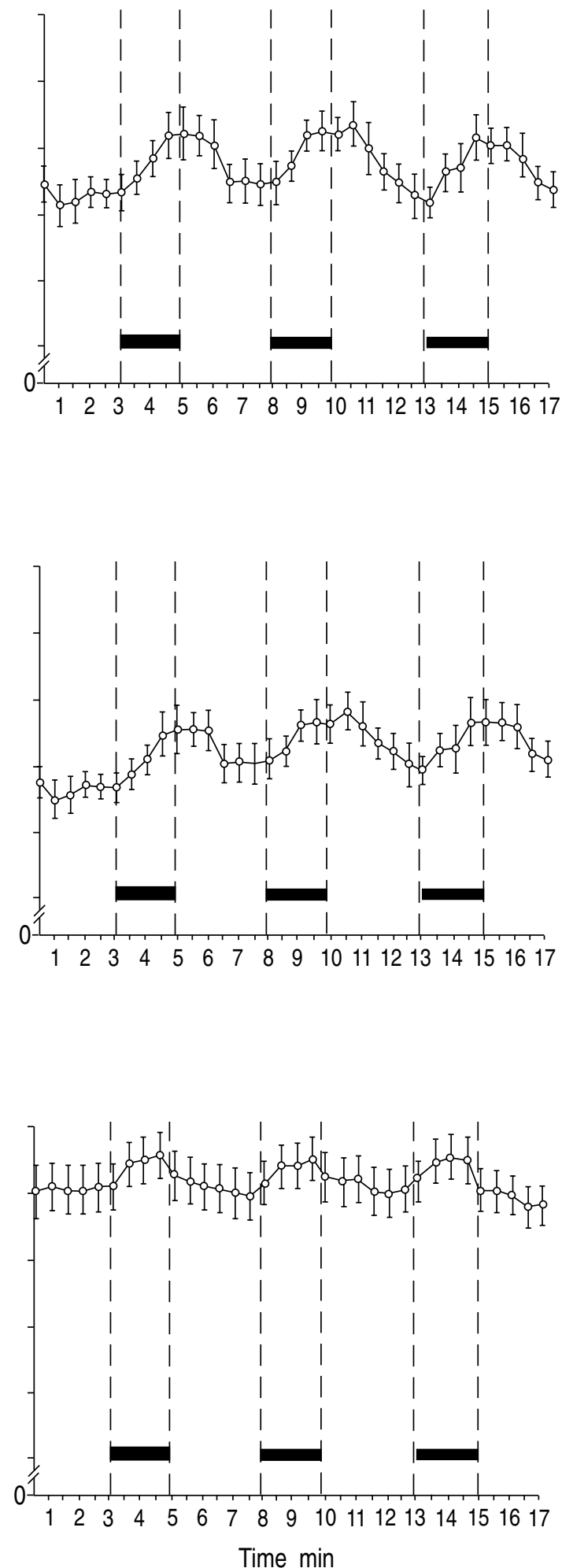

Fig. 2. - Changes in $V^{\prime} \mathrm{O}_{2}, V^{\prime} \mathrm{CO}_{2}$ and $\mathrm{HR}$ during arm elevation testing in healthy subjects ( $\left.\longrightarrow\right)$ and in COPD patients $(\longrightarrow-)$. Data are presented as mean \pm SEM. Each black box on the $\mathrm{x}$-axis indicates a 2 min period of elevation. $0-3$ min: baseline measurements; $3-8$ min: AE 1 and recovery; 8-13 min: $\mathrm{AE} 2$ and recovery; $13-17 \mathrm{~min}$ : $\mathrm{AE} 3$ and recovery. $V^{\prime} \mathrm{O}_{2}$ : oxygen consumption; $V^{\prime} \mathrm{CO}_{2}$ : carbon dioxide elimination; $\mathrm{COPD}$ : chronic obstructive pulmonary disease; AE: arm elevation; HR: heart rate. For further abbreviations see legend to figure 1. 
Healthy

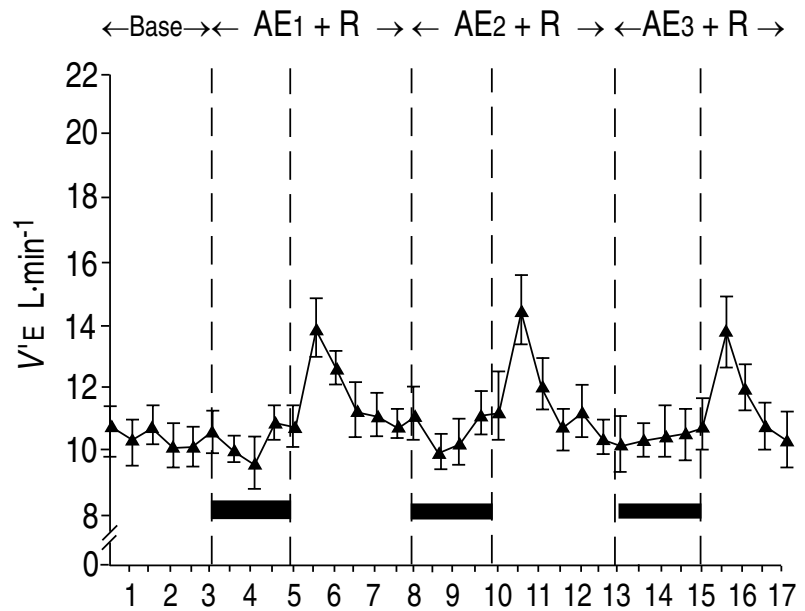

COPD

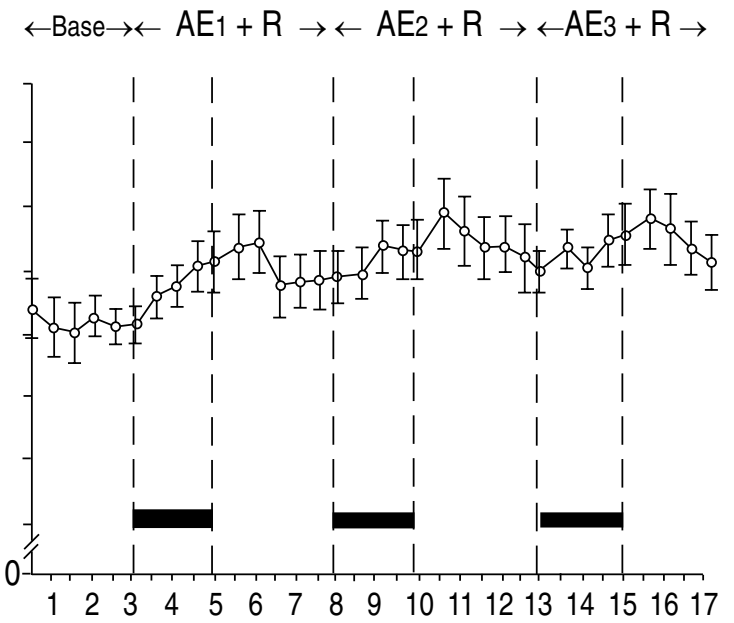

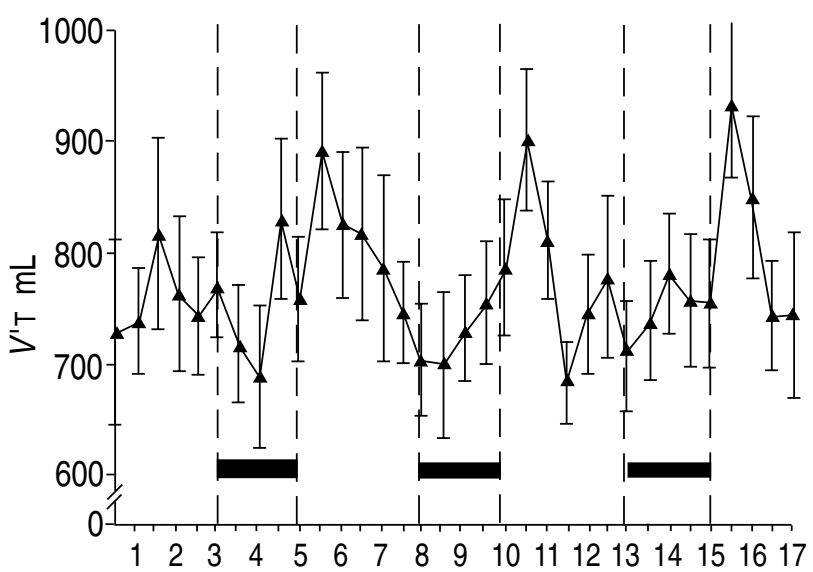
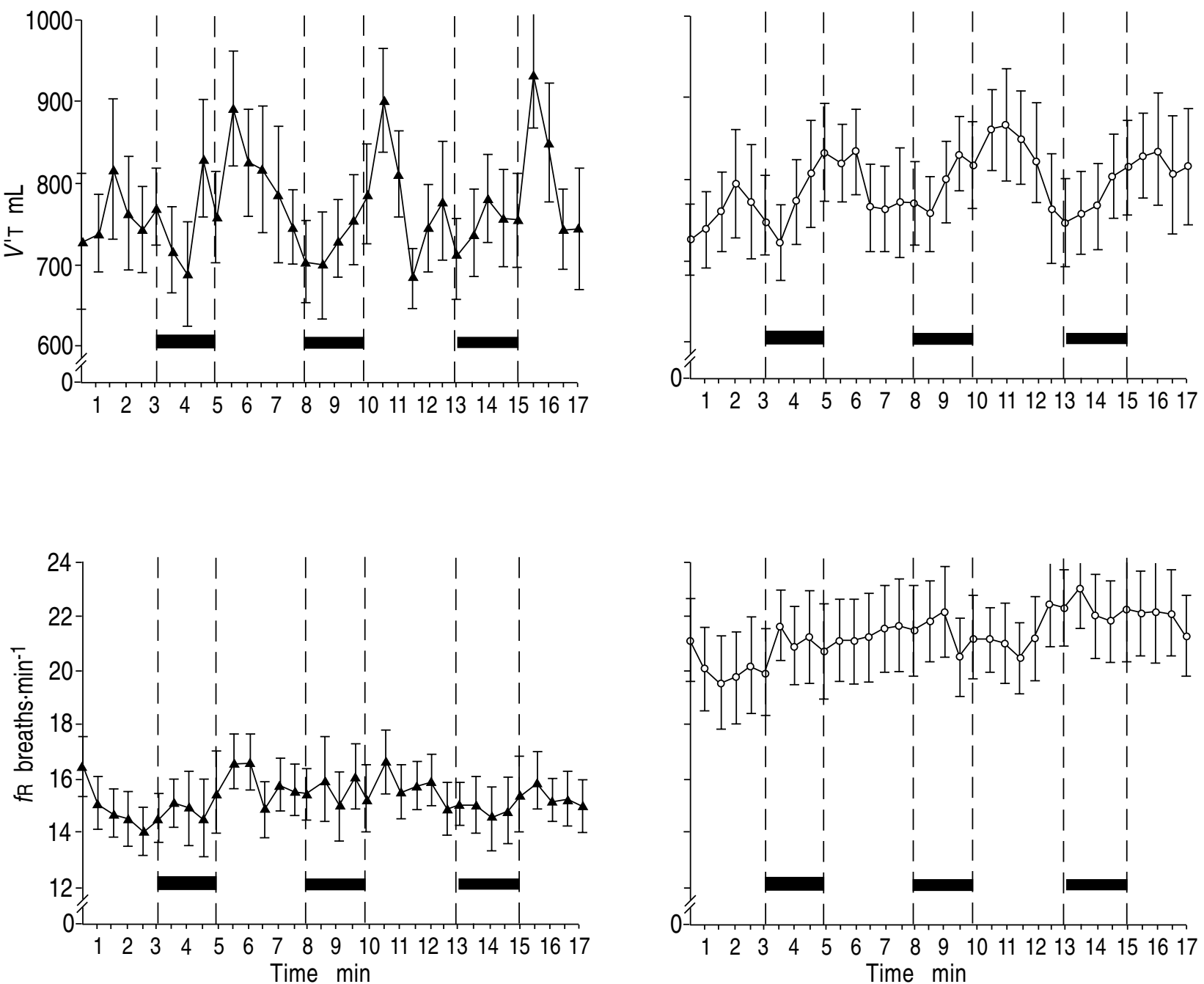

Fig. 3. - Changes in $V^{\prime} \mathrm{E}, V^{\prime} \mathrm{T}$ and $f_{\mathrm{R}}$ during arm elevation testing in healthy subjects (——) and in COPD patients (—- - ). Data are presented as mean \pm SEM. Each black box on the $\mathrm{x}$-axis indicates a 2 min period. $0-3$ min: baseline measurements; 3-8 min: AE1 and recovery; 8-13 min: AE2 and recovery; $13-17$ min: AE3 and recovery. $V$ 'E: minute ventilation; $V$ 'T: tidal volume; $f_{\mathrm{R}}$ : respiratory frequency. For further abbreviations see legend to figures 1 and 2. 
The following calculations were performed in order to interpret the test results: 1) the metabolic and ventilatory requirements during each $\mathrm{AE}$ and the following recovery period; and 2) percentage increase of metabolic and ventilatory parameters for each AE. To adjust for differences between healthy subjects and COPD patients at baseline (i.e. during the first $3 \mathrm{~min}$ of test) the mean baseline test-result was subtracted from the mean metabolic and ventilatory requirement of each AE.

\section{Data analysis}

The characteristics of the two groups are given as mean \pm SD, whereas figures show mean \pm SEM. Differences between groups were tested by Mann-Whitney U-test. Differences within groups were tested by Wilcoxon (for comparisons of two variables) or Friedman (for comparison of more than two variables). The level of significance was determined at $5 \%$.

\section{Results}

\section{Baseline characteristics of the study groups}

The patients studied suffered from severe airflow obstruction as shown in table 1. FFM and body mass were significantly lower in COPD patients compared to the healthy subjects. In COPD patients, REE adjusted for FFM [10] was significantly elevated and maximal inspiratory mouth pressure $\left(P_{\mathrm{I}, \mathrm{max}}\right)$ was decreased.

Baseline results (the mean value of the first $3 \mathrm{~min}$ of the test) were significantly higher in COPD patients compared to healthy subjects for oxygen consumption $\left(V^{\prime} \mathrm{O}_{2}\right.$ : COPD 5.8 \pm 1.1 ; healthy $4.4 \pm 0.9 \mathrm{~mL} \cdot \mathrm{min}^{-1} \cdot \mathrm{kg}$ FFM; $\mathrm{p}<0.01)$, carbon dioxide elimination $\left(V^{\prime} \mathrm{CO}_{2}\right.$ : COPD 5.0 \pm 1.0 ; healthy $3.7 \pm 0.8 \mathrm{~mL} \cdot \mathrm{min}^{-1} \cdot \mathrm{kg} \mathrm{FFM}$; $\left.\mathrm{p}<0.01\right)$, minute ventilation ( $V^{\prime}$ E: COPD $14.4 \pm 2.5$; healthy $10.7 \pm 2 \mathrm{~L} \cdot \mathrm{min}^{-1}$; $\mathrm{p}<0.001)$, respiratory frequency $\left(f_{\mathrm{R}}\right.$ : COPD $20.1 \pm 5.5$; healthy $15.0 \pm 3.2$ breaths $\left.\cdot \mathrm{min}^{-1} ; \mathrm{p}<0.05\right)$ and heart rate (HR: COPD 95.4 \pm 13.2 ; healthy $68.8 \pm 26.1$ beats $\cdot \mathrm{min}^{-1}$; $\mathrm{p}<0.001)$

\section{Results of arm elevation testing}

As the recovery periods after $\mathrm{AE} 1$, (and/or) $\mathrm{AE} 2$ and (or) AE3 showed significantly higher than baseline values of $V^{\prime} \mathrm{E}$, respiratory quotient (RQ), and HR in COPD patients, and of RQ in healthy subjects, only AE1 (table 2) was used to compare the effect of arm elevation in patients and controls. In COPD patients as well as in healthy subjects, $V^{\prime} \mathrm{O}_{2}, V^{\prime} \mathrm{CO}_{2}, \mathrm{RQ}$, HR and $V^{\prime} \mathrm{E}$ were significantly higher than baseline during AE1.

There were no statistically significant differences between the groups in the percentage increase of any metabolic or ventilatory parameter.

Figures 2 and 3 show the response patterns during the time course of arm elevation. In COPD patients $V^{\prime} \mathrm{O}_{2}$, $V^{\prime} \mathrm{CO}_{2}, V^{\prime} \mathrm{E}$, tidal volume $(V \mathrm{~T})$ and $\mathrm{HR}$ gradually increased and decreased, whereas in the healthy control subjects a sudden peak was demonstrated (except for HR). In both groups, RQ increased after each arm elevation, and did not return to resting RQ.

\section{Difference between the three types of arm elevation}

There were some minor differences between the three types of arm elevation which were due to an incomplete recovery between $\mathrm{AE} 1$ and $\mathrm{AE} 2$ and between $\mathrm{AE} 2$ and AE3. Although, in absolute terms, these differences were not large, they did reach statistical significance for $V^{\prime} \mathrm{CO}_{2}$, RQ and $V^{\prime} \mathrm{E}$ in the COPD patients, and for RQ in the healthy subjects. These results were all nearly in parallel with the differences between recovery periods and baseline test results.

\section{Discussion}

In this study, the metabolic and ventilatory requirements of three types of arm elevation were compared between COPD patients and age-matched, healthy subjects. Adjusted for significantly greater baseline values in COPD patients, it was found that $\mathrm{AE}$ (arm elevation including recovery) tended to be more demanding with respect to metabolic and ventilatory response for patients with COPD than for the age-matched healthy subjects. A pronounced difference was found in the pattern of metabolic and ventilatory response to arm elevation between the two groups. Mutual comparison of the three different types of arm elevation demonstrated a comparable response pattern, although due to an incomplete recovery (especially in COPD patients) $V^{\prime} \mathrm{CO}_{2}, V^{\prime} \mathrm{E}$ and $\mathrm{RQ}$ at AE1 were lower than AE2 and (or) AE3.

It is known in healthy persons arm exercise is relatively more demanding than leg exercise since, at a given work output, heart rate, systolic and diastolic pressure, minute ventilation, oxygen uptake, respiratory exchange ratio and blood lactate concentration are higher, whilst stroke volume, anaerobic threshold [15] and mechanical efficiency [16-18] are lower. Furthermore, a disproportionate increase in the diaphragmatic contribution to the generation of ventilatory pressures has been observed during arm elevation by Couser et al. [5]. Another study showed increases in electromyographic amplitudes of trapezius and supraspinatus muscles during arm elevation, and a rapid decrease in the median frequency, suggesting that arm elevation is a fatiguing task for the muscles involved [19].

The arms are needed for many activities of daily living, such as lifting, bathing, dressing, combing hair, hanging out the washing, or gardening [20]. TANGRI and Woolf [1] found that patients with COPD manifest a marked dyspnoea after simple arm movements. Furthermore, CELLI et al. [2] have shown that unsupported arm exercise (UAE) is more difficult to sustain than leg exercise. In several studies, UAE and arm elevation resulted in alterations in breathing pattern [2, 5, 21]. This was confirmed in a study by Dolmage et al. [4], who found 
that even arm positioning only (arms elevated but supported by a sling) changed breathing pattern in COPD patients (decrease in $V_{\mathrm{T}}$, increase in $f_{\mathrm{R}}$ ). In addition, MARTINEZ et al. [8] found that except for an increased diaphragmatic recruitment, COPD patients probably also recruite expiratory muscles during arm elevation.

In this study, arm elevation resulted in a significant increase in $V^{\prime} \mathrm{O}_{2}, V^{\prime} \mathrm{CO}_{2}, \mathrm{RQ}, \mathrm{HR}$ and $V^{\prime} \mathrm{E}$ compared to baseline. This is in accordance with earlier studies [5, 8], although the percentage increases in $V^{\prime} \mathrm{O}_{2}, V^{\prime} \mathrm{CO}_{2}, V^{\prime} \mathrm{E}$ and HR in these studies were much higher than reported here. Instead of calculating peak metabolic and ventilatory response in these earlier studies, we calculated the mean increase of the total period of arm elevation and recovery. We chose to calculate the mean increase because (peak) response to AE was individually different within each group, and clearly between the groups. We could not confirm the data of MARTINEZ et al. [8] who reported that an increase in $V^{\prime} \mathrm{E}$ was caused predominantly by an increase in $f_{\mathrm{R}}$. In our study, $V_{\mathrm{T}}$ and $f_{\mathrm{R}}$ did not significantly increase compared to baseline values in patients or healthy subjects, suggesting that both are determining factors of minute ventilation, as was also reported by DolmaGe et al. [4].

The pattern of metabolic and ventilatory response to AE was clearly different between the groups. The healthy subjects demonstrated a sudden peak in $V^{\prime} \mathrm{O}_{2}$ $V^{\prime} \mathrm{CO}_{2}$ and $V^{\prime} \mathrm{E}$ after AE, but, in contrast to the COPD patients, the onset of the increase was relatively late. In $\mathrm{AE}$ a later adjustment of $V^{\prime} \mathrm{O}_{2}$ would be expected, since AE represents a relatively low "workload" and the rate of $V^{\prime} \mathrm{O}_{2}$ response is lower to a smaller workload than to a great workload [22]. Furthermore, arm exercise usually shows a sluggish $V^{\prime} \mathrm{O}_{2}$ adaptation compared to leg exercise [23]. The quicker response to $\mathrm{AE}$ in the COPD patients is, therefore, surprising. Several explanations are possible for this earlier but more sluggish response pattern seen in COPD patients. Many studies have shown that, in untrained subjects, the kinetics of adjustment of $V^{\prime} \mathrm{O}_{2}$ are markedly delayed [24] and can increase by training [25].

In a study by CERRETELLi et al. [25] it was concluded that this was due to factors involved in $\mathrm{O}_{2}$ conductance from the capillary to the muscle (such as an increased capillary to fibre exchange surface, an increased myoglobin concentration, and a greater enzymatic oxidative potential associated with mitochondrial changes), change in fibre type (reducing glycolysis) [26]. COPD patients use accessory breathing muscles almost constantly to breathe, and this may cause such a training effect. In animal studies, malnutrition has shown a relative increase of type I fibres $[27,28]$. Since, in this study, the COPD patients suffered from tissue depletion compared to the healthy subjects, differences in fibre composition may have been a contributing factor to an earlier metabolic adaptation in the patients. On the other hand, the COPD patients also showed a slower recovery, which is more difficult to interpret.

Another possible explanation for the different response pattern is derived from the fact that pre-existing moderate work by a given muscle group has been demonstrated to accelerate its $V^{\prime} \mathrm{O}_{2}$-onset response [29, 30], especially at lower workloads [24]. Because COPD patients could use shoulder girdle muscles in breathing (already at rest) as well as in arm positioning, this could have enhanced an earlier onset of the metabolic response.

Thirdly, the earlier $V^{\prime} \mathrm{O}_{2}$-onset in COPD patients could be the result of different $V^{\prime}$ E-kinetics compared to healthy subjects. It has been shown in a study by CELLi et al. [2] that arm exercise leads to dyssynchronous breathing in COPD patients. Therefore, problems in co-ordinating breathing could have resulted in an earlier rise in $V^{\prime} \mathrm{E}$ and $V^{\prime} \mathrm{O}_{2}$ in the COPD patients.

There were differences in baseline metabolism and ventilation between COPD patients and healthy subjects prior to the arm elevation testing, despite comparable test conditions. In several studies [10, 31, 32], it was found that COPD patients demonstrate a significantly higher resting energy expenditure than healthy subjects. Although it is clear that a 15-20 min REE-measurement under strict conditions is not the same as a baseline test measurement (of $3 \mathrm{~min}$ ), it can be hypothesized that the significantly increased baseline test results in the COPD patients were a reflection of the increased REE.

In addition, the percentage increase during AE1 also tended to be higher for metabolic variables in patients with COPD compared to healthy subjects. It has been demonstrated in several studies $[33,34]$ that COPD patients have a reduced respiratory mechanical efficiency. This, together with the dual demand of the shoulder girdle muscle in ventilation and postural activities, may result in an increased metabolism during arm elevation. A disproportionate increase in $V^{\prime} \mathrm{E}$ may have been the result of the dual demand of shoulder girdle muscle (difficulties in co-ordinating breathing), but may also be explained by an increased dead space ventilation in the COPD patients.

In conclusion, when adjusted for the increased baseline test results in the COPD patients, arm elevation in COPD patients tended to result in a greater metabolic and ventilatory response than healthy persons. This could be explained by a reduced respiratory mechanical efficiency, a dual activity of shoulder girdle muscle in COPD and an increased dead space ventilation. The response pattern was clearly different between the groups. The healthy subjects demonstrated a peak approximately $30 \mathrm{~s}$ after AE. In the COPD patients, an earlier response of $V^{\prime} \mathrm{O}_{2}$ was observed following arm elevation, which could be explained by tissue depletion, the dual activity of shoulder girdle muscle, and a difference in $V^{\prime}$ E kinetics in COPD patients. Knowledge of the specific response to $\mathrm{AE}$ in COPD patients seems essential for interpretation of arm elevation tests in upper extremity rehabilitation programmes.

\section{References}

1. Tangri S, Woolf CR. The breathing pattern in chronic obstructive lung disease during performance of some common daily activities. Chest 1973; 63: 126-127. 
2. Celli BR, Rassulo J, Make BJ. Dyssynchronous breathing during arm but not leg exercise in patients with chronic airflow obstruction. N Engl J Med 1986; 314: 1485-1490.

3. Criner GJ, Celli BR. Effect of unsupported arm exercise on ventilatory muscle recruitment in patients with severe airflow obstruction. Am Rev Respir Dis 1988; 138: 856-861.

4. Dolmage TE, Maestro L, Avendano MA, Goldstein RS. The ventilatory response to arm elevation of patients with chronic obstructive pulmonary disease. Chest 1993; 104: 1097-1100.

5. Couser JI, Maryinez FJ, Celli BR. Respiratory response and ventilatory muscle recruitment during arm elevation in normal subjects. Chest 1992: 101: 336-340.

6. Kilian KJ, LeBlanc P, Martin DH, Summers E, Jones NL, Campbell EJM. Exercise capacity and ventilatory, circulatory, and symptom limitation in patients with chronic airflow limitation. Am Rev Respir Dis 1992; 146: 935-940.

7. Janssens S, Decramer M. Corticortsteroid induced myopathy and the respiratory muscle. Chest 1989; 95: 11601162.

8. Martinez FJ, Couser JI, Celli BR. Respiratory response to arm elevation in patients with chronic airflow obstruction. Am Rev Respir Dis 1991; 143: 476-480.

9. Medical section of the American Lung Association. Standards for the diagnosis and care of patients with chronic obstructive pulmonary disease (COPD) and asthma. Am Rev Respir Dis 1987; 134: 239-243.

10. Schols AMWJ, Fredrix EWHM, Soeters PB, Westerterp KR, Wouters EFM. Resting energy expenditure in patients with chronic obstructive pulmonary disease. Am J Clin Nutr 1991; 54: 983-987.

11. Quanjer PH, ed. Standardised lung function testing. Bull Eur Physiopathol Respir 1983; 19: 7-44.

12. Black LF, Hyatt RE. Maximal respiratory pressures: normal values and relation to age and sex. Am Rev Respir Dis 1969; 99: 696-702.

13. Lukaski HC, Bolonchuk WW, Hall CB, Siders WA. Validation of tetrapolar bioelectrical impedance method to assess human body composition. J Appl Physiol 1986; 60: 1327-1332.

14. Schols AMWJ, Wouters EFM, Soeters PB, Westerterp KR. Body composition by bioelectrical-impedance analysis compared with deuterium dilution and skinfold anthropometry in patients with chronic obstructive pulmonary disease. Am J Clin Nutr 1991; 53: 421-424.

15. Franklin BA. Exercise testing, training and arm ergometry. Sports Med 1985; 2: 100-119.

16. Jensen M, Ahlborg G. Is the high lactate release during arm exercise due to a low training status. Clin Physiol 1992; 12: 487-496.

17. Jensen-Urstad M, Hallback I, Sahlin K. High anaerobic energy release during submaximal arm exercise. Clin. Physiol 1993; 13: 81-87.

18. Bevergard S, Preyschuss U, Strandell T. Circulatory adaptation to arm and leg exercise in supine and sitting position. J Appl Physiol 1966; 21: 37-46.

19. Harberg M. Electromyographic signs of shoulder muscle fatigue in two elevated arm positions. Am J Phys Med 1981; 69: 111-121.

20. Lake FR, Henderson K, Briffa T, Openshaw J, Musk W. Upper limb and lower limb exercise training in patients with chronic airflow limitation. Chest 1990; 97: 10771082.

21. Maestro L, Dolmage T, Avendano M, Goldstein R. Influence of arm position in ventilation during incremental exercise in healthy individuals. Chest 1990; 98 : $113 \mathrm{~s}$.

22. Whipp BJ, Wasserman K. Oxygen uptake kinetics for various intensities of constant-load work. J Appl Physiol 1972; 28: 452-456.

23. Cerretelli P, Shindell D, Pendergast DP, Prampero PE, Rennie DW. Oxygen uptake transients at the onset and offset of arm and leg work. Respir Physiol 1977; 30: 81-97.

24. Pendergast DR. Cardiovascular, respiratory, and metabolic responses to upper body exercise. Med Sci Sports Exerc 1989; 21 (Suppl. 5): s121-s125.

25. Cerretelli P, Pendergast D, Paganelli WC, Rennie DW. Effects of specific muscle training on $V^{\prime} \mathrm{O}_{2}$ response and early blood lactate. J Appl Physiol: Respirat Environ Exercise Physiol 1979; 47: 761-769.

26. Andersen P, Hendriksson J. Capillary supply of the quadriceps femoris muscle in man: adaptive response to exercise. J Physiol (Lond) 1977; 270: 677-690.

27. Sieck GC, Lewis MI, Blanco CE. Effects of undernutrition on diaphragm fiber size, SDH activity, and fatigue resistance. J Appl Physiol 1989; 66: 2196-2205.

28. Kelsen SG, Ference M, Kapoor S. Effects of prolonged undernutrition on structure and function of the diaphragm. J Appl Physiol 1985; 58: 1354-1359.

29. di Prampero PE, Davies M, Cerretelli P, Margaria R. An analysis of $\mathrm{O}_{2}$ debt contraction in submaximal exercise. J Appl Physiol 1970; 29: 547-551.

30. Karlsson J, Bonde-Peterson F, Hendrikssoon Jr J, Knottgen HJ. Effects of previous exercise with arms or legs on metabolism and performance in exhaustive exercise. J Appl Physiol 1970; 28: 397-406.

31. Goldstein SA, Askanazi J, Weissman C, Thomashow B, Kinney J. Energy expenditure in patients with chronic obstructive pulmonary disease. Chest 1987; 91: 222-224.

32. Fitting JW, Frascarolo $\mathrm{Ph}$, Jéquier E, Leuenberger $\mathrm{Ph}$. Energy expenditure and rib cage abdominal motion in chronic obstructive pulmonary disease. Eur Respir $J$ 1989; 2: 840-845.

33. Cherniack RM. The oxygen consumption and efficiency of the respiratory muscles in health and emphysema. $J$ Clin Invest 1959; 38: 494-499.

34. Levison H, Cherniack RM. Ventilatory cost of exercise in chronic obstructive pulmonary disease. J Appl Physiol 1968; 25: 21-27. 